\title{
CARACTERIZAÇÃO DO SISTEMA DE PRODUÇÃO CAPRINO E OVINO NA REGIÃO SUL DO ESTADO DO MARANHÃO, BRASIL
}

\author{
Aldivan Rodrigues Alves ${ }^{1}$ \\ Marcio da Silva Vilela ${ }^{2}$ \\ Maria Verônica Meira de Andrade ${ }^{1}$ \\ Liduina da Silva Pinto ${ }^{3}$ \\ Djonata Brito de Lima ${ }^{2}$ \\ Lailson Lucas Lopes Lima
}

\begin{abstract}
RESUMO
Objetivou-se caracterizar o sistema de produção da ovinocaprinocultura desenvolvido na região sul do estado do Maranhão, Brasil. Foram realizadas entrevistas aos produtores utilizando-se questionários para caracterização das propriedades rurais relacionadas aos indicadores físicos, sociais, financeiro, dados produtivos e para avaliar os diversos aspectos do sistema de alimentação. O estudo compreendeu a criação de um banco de dados, para realização de análise tabular associada ao estudo descritivo, agrupando-se todas as propriedades visitadas. As propriedades têm em média 146 hectares com um rebanho médio de 46 e 51,4 cabeças de ovinos e caprinos, respectivamente. Apresentaram semelhança nos aspectos sociais, infraestrutura e sistema de manejo com características de atividade de subsistência e têm a produção de carne como produto principal, com demanda de assistência técnica e baixo nível tecnológico. A base alimentar dos animais consiste no pasto nativo associado ao pasto cultivado com fornecimento de concentrado sem considerar os aspectos nutricionais.
\end{abstract}

Palavras-chave: caprinos, ovinos, sistemas de produção.

\section{CHARACTERIZATION OF THE GOAT AND SHEEP PRODUCTION SYSTEM IN THE SOUTH REGION OF THE STATE OF MARANHÃO, BRAZIL}

\begin{abstract}
We aimed to characterize the goat and sheep productive systems developed in the southern of Maranhão, Brazil. Interviews were conducted with producers using questionnaires to characterization the properties related to indicators to physical, social, financial, productive data and to explain various aspects of the feeding system. The study involved the creation of a database for conducting tabular analysis associated with the descriptive study, grouping all the farms visited. The properties have an average of 146 hectares area with a cattle average of 46 and 51.4 head of sheep and goats, respectively. Showed similarities in the social aspects, infrastructure and management system with characteristics of subsistence activity and the meat is the main product, with demand of technical assistance and low technological level. The base feeding of animals consists in the native pasture associated with cultivated pasture with supply of concentrated without considering the nutrition aspects.
\end{abstract}

Keywords: goats, sheep, productive systems.

\footnotetext{
${ }^{1}$ Diretoria de Desenvolvimento ao Ensino, Instituto Federal do Maranhão - Campus Caxias. Rodovia MA 349, Km 02, Gleba do Paraíso, Povoado Lamego, Zona Rural - Caxias -MA, CEP: 65.600-992. Brasil. Contato correspondência.

${ }^{2}$ Diretoria de Desenvolvimento ao Ensino, IFMA-Campus São Raimundo das Mangabeiras. Zootecnia.

${ }^{3}$ Discente da Universidade Federal da Paraíba, Departamento de Letras, UEMA/Caxias.
} 


\section{CARACTERIZACIÓN DEL SISTEMA DE PRODUCCIÓN DE GANADO CAPRINO Y OVINO EN LA REGIÓN SUR DEL ESTADO MARANHÃO, BRASIL}

\section{RESUMEN}

El objetivo de este trabajo fue caracterizar el sistema de producción de ganado ovino y caprino en la región sur del estado de Maranhao, Brasil. Se realizaron entrevistas a los productores por medio de cuestionarios para caracterizar las propiedades rurales relacionados con los indicadores físicos, sociales, datos financieros y productivos para explicar los diversos aspectos del sistema de alimentación. El estudio implicó la creación de una base de datos para la realización de análisis tabular asociada con el estudio descriptivo, agrupando todas las granjas visitadas. Las propiedades tienen un promedio de 146 hectáreas con un rebaño promedio de 46 y 51,4 cabezas de ganado ovino y caprino, respectivamente. Ellos fueron similares en los ámbitos social, infraestructura y sistema de gestión con características de la actividad de subsistencia y tienen la producción de carne como producto principal, con la demanda de servicios y de bajo nivel tecnológico. La base de la alimentación de los animales consiste en pastos nativos asociados con la pastura cultivada con suministro de concentrado sin tener en cuenta los aspectos nutricionales.

Palabras clave: cabras, ovelhas, sistemas de producción.

\section{INTRODUÇÃO}

A ovinocaprinocultura fornece aos produtores rurais proteína de alto valor biológico e renda, resultando em avanço econômico e social das regiões, garantindo a permanência do homem no campo e diminuindo a superpopulação nas cidades que gera mão-de-obra ociosa e aumento da pobreza. Segundo o IBGE (1) do efetivo nacional de ovinos e caprinos correspondente a 16,8 e 9,2 milhões de cabeças, respectivamente, aproximadamente 232 mil ovinos estão no Maranhão o que representa apenas $1,4 \%$ e um pouco mais para espécie caprina com 385 mil ou 4,2\% do total. Estes dados demonstram uma importante capacidade de expansão da exploração da ovinocaprinocultura no estado podendo tornar-se uma das potencialidades da produção pecuária a exemplo da bovinocultura de corte.

De modo geral a exploração desta atividade em toda região nordeste baseia-se em sistemas extensivos caracterizados pelo uso excessivo da pastagem nativa e uso reduzido de técnicas de manejo que envolve os aspectos reprodutivos, sanitários e principalmente alimentar o que resulta em baixos índices produtivos. Gonçalves et al. (2) enfatizam por exemplo que dentre os principais fatores que limitam o aumento da produtividade e da oferta de leite caprino é a nutrição e a alimentação dos rebanhos.

Com o intuito de possibilitar o estudo de grande grupo de fatores ao mesmo tempo e de forma coerente, tem sido proposto considerar o sistema de produção o qual envolve o sistema de alimentação, composto por dois subsistemas: decisional e o biotécnico. O subsistema decisional é o que "dirige" o sistema de produção, seu elemento fundamental é o proprietário ou pessoa responsável pelas tomadas de decisões (3). O subsistema biotécnico é constituído pelo rebanho e pastagens (parte biológica do sistema) que determinam as respostas aos alimentos consumidos (4), podendo sofrer influência do meio ambiente. O elo de ligação entre estes dois subsistemas são as práticas realizadas pelo homem. Há uma hierarquia, onde o subsistema decisional é superior ao subsistema biotécnico. Este enfoque possibilita acessar as estratégias de alimentação a partir da análise das práticas de alimentação do rebanho realizadas pelo produtor. 
Além do mais conhecer os alimentos que fazem parte da dieta dos animais nestes sistemas é fundamental para melhorar a produtividade e o custo/benefício ao longo do ano, pois os alimentos possuem características particulares e interações complexas que refletem diretamente na produção animal, além disso, a utilização racional dos alimentos evita o uso de nutrientes em excesso melhorando a lucratividade, competitividade e sustentabilidade da atividade. Apesar da utilização de concentrado pelos produtores, seu uso consiste apenas no fornecimento de concentrados prontos onde, geralmente, cada ingrediente é fornecido isoladamente, sem maiores preocupações com o atendimento das exigências nutricionais por categoria (animais em fases de crescimento, lactação, reprodução, etc.) (5).

Objetivou-se com este estudo caracterizar o sistema de produção quanto aos aspectos sociais, físicos e de manejo alimentar da ovinocaprinocultura desenvolvido na região sul do estado do Maranhão, Brasil.

\section{MATERIAL E MÉTODOS}

O trabalho foi desenvolvido na região da chapada, Sul do Maranhão (6). O clima dessa área é classificado como quente e úmido, com duas estações bem definidas, uma chuvosa e outra seca. A temperatura média anual da região é em torno de $26{ }^{\circ} \mathrm{C}$, com amplitude anual inferior a $5^{\circ} \mathrm{C}$, que caracteriza o regime térmico da região com pequena variação estacional durante o ano (7). O cerrado com os seus grupos (Cerradão, Campo Cerrado e Parque) constituem a vegetação dessa região (8).

A inexistência de uma listagem representativa dos criadores de caprinos e ovinos tornou impossível a amostragem aleatória. Assim, utilizou-se a amostragem probabilística por conveniência para selecionar os produtores, mediante levantamento prévio, levando-se em consideração o tamanho da propriedade, o tempo dedicado a ovinocaprinocultura e o número de animais que caracterizam os sistemas de alimentação desenvolvidos. Foram selecionadas 11 propriedades no município de São Raimundo das Mangabeiras, as propriedades foram distribuídas equitativamente em cada um dos quatro pontos cardinais (norte, sul, leste e oeste) e região central.

Foram realizadas entrevistas aos proprietários ou responsáveis pela atividade utilizandose um questionário global (estruturado), denominado questionário 1, aplicado uma única vez, para caracterização das propriedades relacionadas aos indicadores físicos, sociais, financeiro/empréstimos e dados produtivos, com duração média de aplicação de trinta a setenta minutos. Outro questionário (estruturado e semiestruturado), questionário 2, também foi aplicado para avaliar os diversos aspectos que norteiam os sistemas de alimentação adotados pelos ovinocaprinocultores, aplicado com periodicidade mensal por 6 meses, com duração média de aplicação de vinte a quarenta minutos.

Para ambos os questionários as entrevistas foram realizadas pela mesma equipe previamente treinada com igual sistemática, evitando-se, assim, erros de interpretação. Durante a aplicação do questionário 2 nas questões/variáveis semiestruturadas, esta foi realizada de forma semidireta em que apenas lançava-se uma questão e deixava-se o produtor discorrer sobro o assunto, segundo a sua lógica, sem interferências excessivas do entrevistador (9), utilizando-se um questionário guia para obter informações não "viciadas".

Para análise dos aspectos globais foram utilizadas 40 questões/variáveis sendo: para caracterização dos aspectos sociais foram utilizadas 12 questões: GF = grau de formação do proprietário; $\mathrm{EC}=$ estado civil; $\mathrm{F}=$ filhos; $\mathrm{QF}=$ quantidade de filhos; $\mathrm{CPRT}=$ condição do produtor em relação ao uso da terra; $\mathrm{RE}=$ residência; $\mathrm{CRE}=$ condição de residência; $\mathrm{ATIV}=$ atividades; TREI $=$ treinamentos; $\mathrm{AT}=$ assistência técnica; $\mathrm{ASSO}=$ associado; $\mathrm{COOP}=$ cooperado. Para os aspectos físicos/infraestrutura foram 11 questões: $\mathrm{AF}=$ área da propriedade; $\mathrm{AP}=$ área destinada a pecuária; $\mathrm{AL}=$ área destinada a lavoura $; \mathrm{DC}=$ distância 
do centro urbano; $\mathrm{DA}=$ disponibilidade de água; $\mathrm{QA}=$ qualidade da água; $\mathrm{EE}=$ disponibilidade de fonte de energia; INS = instalações; TINS = tipo de instalações; INSC = instalações separadas por categoria; IPPV= instalações que permite práticas veterinárias. Quanto aos aspectos econômicos de financiamentos 3 questões: FINAN = financiamento; $\mathrm{FON}=$ fonte/tipo de financiamento e ROA $=$ recursos de outras atividades. Por fim os aspectos produtivos com 14 questões: $\mathrm{L}=$ lavouras; $\mathrm{DL}=$ destino do produto das lavouras; $\mathrm{F} 1$ = feijão; $\mathrm{M}=$ milho; $\mathrm{A}=$ arroz; $\mathrm{MA}=$ macaxeira $\mathrm{CA}=$ cana; $\mathrm{MAN}=$ mandioca; $\mathrm{FR}=$ fruticultura; $\mathrm{B}=$ bovinos; $\mathrm{C}=$ caprinos; $\mathrm{O}=$ ovinos; $\mathrm{OU}=$ outros animais e $\mathrm{APT}=$ aptidões das criações).

Foi considerado como "fase de alimentação" período (mês) no qual não há alteração nas práticas de alimentação: tipo e quantidade de alimentos volumosos e/ou concentrados, mudança de área de pastejo e razão de fornecimento de concentrado (kg/animal/dia). A partir do estudo das fases de alimentação foram verificadas as variáveis referentes à base alimentar volumosa e suplementar ao longo dos meses que buscou identificar aquelas com potencial para explicar de forma satisfatória a diversidade de sistemas de alimentação.

Nos dados gerados a partir das informações das variáveis explicativas da diversidade das características das propriedades relacionadas aos indicadores físicos, sociais, financeiro/empréstimos, dados produtivos e das estratégias de alimentação foi aplicada uma análise descritiva por meio de Planilhas Base de Dados desenvolvidas no Excel 2010.

\section{RESULTADOS E DISCUSSÃO}

Das 11 propriedades apenas uma é exclusiva produtora de ovinos (9\%), das restantes quatro criam ovinos e caprinos (36\%), simultaneamente, e seis exclusivamente caprinos (55\%). De modo geral as propriedades produtoras de ovinos e caprinos na região sul do Maranhão têm em média 146 hectares (variando de 50 a 421 hectares), distantes aproximadamente $40 \mathrm{~km}$ dos centros urbanos e com um rebanho médio de 46 e 51,4 cabeças de ovinos e caprinos, respectivamente, sendo encontrados produtores com rebanhos variando de 15 a 90 cabeças.

Verificou-se que as propriedades que tiveram uma diferenciação expressiva em relação às demais, principalmente, pelas características físicas AF (área da propriedade) e AP (área destinada a pecuária) com maior AF e AP, apresentaram menor relação entre a quantidade de animais por área com 0,14 animais por hectare, mostrando uma subutilização de áreas que poderiam ser melhores trabalhadas para o desenvolvimento da ovinocaprinocultura, resultados que corroboram com os encontrados por Costa et al., (5), com relação à caracterização do sistema de produção da ovinocaprinocultura na região do Cariri Paraibano, ao afirmarem que os produtores de ovinos e caprinos com maior área disponível além de água e área construída nas propriedades são os que mais subutilizam os recursos das propriedades e seus respectivos potenciais.

Aspectos fundamentais foram comuns a todas as propriedades estudadas como a disponibilidade de água doce e provenientes de riachos, apenas uma propriedade possui açude como fonte de reservatório para água. Este fato deve-se a grande riqueza de recursos hídricos do Maranhão que tem como rios principais o rio das Balsas, Gurupi, Itapecuru, Mearim, Parnaíba, Pindaré, Tocantins, Turiaçu (10).

De acordo com Faria et al. (11), em estudo realizado para levantamento do perfil da ovinocaprinocultura desenvolvida no semiárido mineiro, as fontes de água de superfície (rios, córregos, açudes, nascente e minas) eram mais utilizadas no Norte do Estado, enquanto os poços rasos e artesianos mais comuns no Nordeste, corroborando com Alencar et al. (12) que encontraram como principal meio utilizado para captar e reservar a água utilizada na 
produção de caprinos e ovinos no sertão do estado de Pernambuco os poços e/ou açudes (83\% dos produtores).

Foi observada em $90 \%$ das propriedades a presença de instalações/aprisco para os animais, sendo deste percentual $80 \%$ do tipo "faxina" caracterizada pela construção com varas provenientes de fontes arbóreas da própria propriedade, dentre o principal material utilizado destaca-se as varas de bambu, e apenas $30 \%$ permitem divisórias por categoria, mas $40 \%$ permitem práticas veterinárias. Vieira et al. (13) realizando estudos em área semiárida, no município de São Miguel do Tapuio - Piauí, também destacam o uso deste tipo de aprisco.

Outros aspectos comuns, entre as propriedades, foram a participação do núcleo familiar, assim como a falta de qualquer treinamento e assistência técnica voltada à produção de ovinos e caprinos. Segundo Medeiros (14), o cenário da caprinocultura no semiárido nordestino, caracteriza-se dentre diversos fatores pela deficiência de assistência técnica; baixo nível de organização; deficiência de tecnologias para nutrição e acabamento dos animais; inadequação do sistema de manejo e falta de análise econômica nos diversos sistemas de produção. Bandeira (15) afirma que a caprinocultura do Estado da Paraíba apresenta-se com um registro promissor de 93,3\% dos produtores que têm acesso à assistência técnica, sendo que 76,8\% ocorre semanal ou quinzenalmente.

Aspectos importantes como participação em cooperativas (COOP), associação (ASSO) e financiamento foi mencionado apenas por um produtor dentre os 11 avaliados, indicando reduzido número de produtores com estas práticas organizacionais. Para Costa (16) o Brasil vive um cenário de muitas transformações, no setor de exploração de pequenos ruminantes, entre eles destacam-se a incorporação de novas formas de organização da produção, a articulação entre os produtores com novas formas de cooperação econômica e tecnológica, assim como novos arranjos, contratos e acordos interempresas, como forma de estabelecer uma coordenação técnica das atividades produtivas, para aproveitar as oportunidades de aprendizado e acúmulo de capacitações na interação entre os envolvidos.

Um percentual de 54,5\% apresentam características bem relevantes para conhecimento do sistema de exploração da ovinocaprinocultura na região estudada, apresentam ensino fundamental completo, associados a uma exploração mista com a presença também da exploração de bovinos (B) e ovinos (O). Alves (17) observou que um dos entraves para o desenvolvimento da ovinocaprinocultura em algumas regiões do Nordeste, deve-se, além da questão cultural, ao baixo nível educacional dos produtores, que geralmente ocasiona resistência a inovações, insuficiente capacitação técnica, gerencial e capacidade de organização, e consequentemente, baixo dinamismo e competitividade. Este grupo apresenta ainda semelhança quanto à residência (RE) em que moram ou na cidade ou na cidade e no campo, associado também ao desenvolvimento de outras atividades (ATIV) não ligadas a caprinocultura, mas sim a atividades desenvolvidas nos centros urbanos. Esses resultados corroboram com Porto et al. (18) ao caracterizarem o perfil de ovinocaprinocultores no centro norte baiano que observaram elevado número de produtores que possuem, além da produção de animais, outra fonte de recursos que também contribuem na renda da propriedade, como: benefícios oriundos do Programa Bolsa Família (37\%) e aposentadorias (14\%), comerciantes (10\%) e funcionários públicos que representaram $15 \%$ que dos que mencionaram possuir fonte de renda complementar.

O sistema de manejo da criação tem influência direta no desempenho animal, pois determina o tempo de pastejo, (de acordo com a Tabela 1). Verificou-se variação no tempo de pastejo de 6 a 24 horas, mas o principal sistema de manejo, adotado por $40 \%$ dos entrevistados, é o Sistema 2 com um tempo de pastejo de 8 horas diária. Costa et al. (5) verificaram predominância das explorações extensivas, sem uso de técnicas de manejo e praticamente sem nenhuma escrituração zootécnica ao caracterizarem o sistema de produção ovino e caprino no Cariri Paraibano - Brasil. No presente estudo não foi encontrado nenhum 
produtor que realize a prática de escrituração zootécnica, mas o sistema tradicional representou apenas $10 \%$ de utilização (Tabela 1).

Não há separação entre machos e fêmeas, sendo que $40 \%$ dos produtores adotam o Sistema 2, com 9 horas de pastejo e caracterizado pelo pastejo no período diurno e estabulação dos animais no período noturno. A exploração de ovinos e caprinos em $100 \%$ é destinada para corte (APT), fato este que justifica a não utilização do manejo separado por sexo. Para Alencar et al. (12) a separação dos animais de um rebanho em lotes de acordo com a idade e sexo, no semiárido do Pernambuco foi de apenas $20,8 \%$ dos rebanhos. Os autores afirmam que, além de facilitar o manejo a separação por idade e sexo, também previne ocorrências indesejáveis como coberturas e disseminação de doenças.

Tabela 1. Tipos de manejo de criação adotados para reprodutores e matrizes praticados pelos criadores de ovinos e caprinos na região das Chapadas - MA.

\begin{tabular}{clc}
\hline Sistemas de Manejo das Criações & Descrição do sistema & Percentual \\
\hline Sistema 1 & Extensivo característico & $10 \%$ \\
Sistema 2 & Pastejo das 08:00h as 17:00 & $40 \%$ \\
Sistema 3 & Pastejo das 10:00h as 17:00 & $20 \%$ \\
Sistema 4 & Pastejo das 11:00h as 18:00 & $20 \%$ \\
Sistema 5 & Pastejo das 12:00h as 18:00 & $10 \%$ \\
& TOTAL GERAL & $\mathbf{1 0 0 \%}$ \\
\hline
\end{tabular}

A tabela 2 apresenta os sistemas de manejo adotado para os animais jovens, em que $60 \%$ dos ovinocaprinocultores permanecem com os animais até 20 dias no curral de manejo, tendo estes, acesso a mãe no período noturno e apenas $10 \%$ que manejam os animais jovens diretamente com os adultos desde os primeiros dias de vida. Dwyer (19) ao determinarem alguns fatores que causam a mortalidade em pequenos ruminantes que ocorre, principalmente, logo após o parto e pode se estender até o desmame, concluíram que além do consumo insuficiente de colostro, e à hipotermia, está a predação. Dessa maneira, a permanência dos animais no curral de manejo nos primeiros dias de vida pode evitar a mortalidade por predadores e pela utilização de práticas profiláticas para redução de doenças.

Tabela 2. Tipos de manejo de criação para animais jovens praticados pelos criadores de ovinos e caprinos na região das Chapadas - MA.

\begin{tabular}{clc}
\hline $\begin{array}{c}\text { Sistemas de manejo } \\
\text { Criações }\end{array}$ & \multicolumn{1}{c}{ Descrição do sistema } & $\begin{array}{c}\text { Percentual } \\
\text { utilizável }\end{array}$ \\
\hline Sistema 1 & $\begin{array}{l}\text { Manejados juntamente com o rebanho } \\
\text { adulto desde o } 1^{\circ} \text { dia de vida }\end{array}$ & $10 \%$ \\
Sistema 2 & $\begin{array}{l}\text { Até 10 dias de vida confinados e acesso a } \\
\text { mãe no período noturno e após juntamente } \\
\text { com o rebanho adulto }\end{array}$ & $20 \%$ \\
Sté 15 a 20 dias de vida confinados e acesso & $60 \%$ \\
Sistema 3 & $\begin{array}{l}\text { a mãe no período noturno e após juntamente } \\
\text { com os adultos } \\
\text { Até 30 dias de vida confinados e acesso a } \\
\text { mãe no período noturno e após juntamente } \\
\text { com o rebanho adulto } \\
\text { TOTAL GERAL }\end{array}$ & $10 \%$ \\
\hline
\end{tabular}

Com relação à base da alimentação volumosa dos ovinos e caprinos encontrou-se a utilização do pastejo direto em pasto nativo ou pasto nativo associado ao pasto cultivado com 
percentuais de 10 e $90 \%$, respectivamente. A utilização das pastagens cultivadas, devido à alta produção obtida, permite a menor utilização dos pastos nativos (20).

Apenas $20 \%$ afirmaram utilizar o feno e $10 \%$ a silagem na alimentação dos seus animais, embora a fenação e a silagem sejam processos simples de conservação de alimentos, podendo ser fornecidos aos animais quando da indisponibilidade de pasto nativo ou cultivado, bem como do concentrado, práticas ainda pouco utilizadas.

Analisando o percentual de caprinocultores que utilizam suplementação alimentar, verificamos que $70 \%$ destes fazem uso do concentrado ou suplemento volumoso. Os principais alimentos concentrados utilizados pelos produtores são: palhada de arroz/cuim; milho moído; farelo de Soja; mandioca; feijão, milho moído e milho com sabugo desintegrado. De acordo com Lima et al. (20) os concentrados possuem de 85 a $95 \%$ de MS e a sua fração energética compreende o amido, os açúcares mais simples e as gorduras, apresentando em geral mais de $65 \%$ de NDT. Eles podem ser divididos em concentrados protéicos e energéticos, quando possuem quantidade maior ou menor que $20 \%$ de proteína, respectivamente. Os alimentos proteicos compreendem os farelos e farinhas de cereais (com 20 a 30\% de proteínas). Em geral, são usados os coprodutos das agroindústrias e da extração de óleo comestível.

Dos ovinocaprinocultores entrevistados nenhum indicou o oferecimento com base na categoria animal, responderam apenas que fornecem a vontade ou em quantidade estabelecida aleatoriamente sem qualquer base de referência nutricional, corroborando com Costa et al. (5) ao afirmarem que apesar da utilização de concentrados pelos produtores, seu uso consiste apenas no fornecimento de concentrados prontos sendo, geralmente, cada ingrediente fornecido isoladamente, sem maiores preocupações com o atendimento das exigências nutricionais por categoria (animais em fases de crescimento, lactação, reprodução, etc.).

Dos caprinocultores, $100 \%$ dos entrevistados afirmaram que fornecem sal mineral aos animais, sendo em torno de $80 \%$ do sal mineral fornecido, constituído de uma mistura de sal comum com núcleos comercias prontos misturados na própria propriedade; $10 \%$ para sal mineral comprado pronto e $10 \%$ apenas fornecem sal comum. Os minerais são imprescindíveis para os animais por participarem como componentes estruturais dos tecidos, por atuarem nos fluidos corporais como eletrólitos para manutenção do equilíbrio ácidobásico, da pressão osmótica e da permeabilidade das membranas celulares (21).

Verificou-se neste trabalho que como categoria há apenas uma fase de alimentação "fase longa" que caracteriza o sistema de alimentação e quatro tipos de sequências de fases (Figura 1), predominando a sequência B representada pela utilização do pasto (nativo ou nativo+cultivado) com suplementação (concentrado e/ou volumoso), esta sequência é realizada por $64 \%$ dos produtores.

As sequências A e D que juntas representam apenas $18 \%$ de utilização são aquelas representadas pela ausência de alterações no manejo alimentar evidenciando que há pouca reatividade do produtor, ponto importante a ser destacado no sistema de alimentação, pois esta reatividade segundo Roehsig (22) indica a frequência e intensidade de alteração nas práticas de alimentação, ou seja, qual o momento em que o indivíduo irá começar a agir frente a um problema. Sistemas produtivos pouco reativos são caracterizados pela ausência de planejamento estratégico no uso de suplementação, seja esta volumosa ou concentrada, e que contribuem para a baixa produtividade dos rebanhos caracterizando-os como sistemas típicos de exploração sem ou com baixo nível tecnológico e ao mesmo tempo sistemas mais reativos demonstram maior nível de planejamento estratégico, mas vale ressaltar que neste trabalho ainda foram encontrados diversos vários entraves no sistema de alimentação dentre eles o fornecimento de concentrado sem considerar nenhum aspecto nutricional como mencionado anteriormente. 

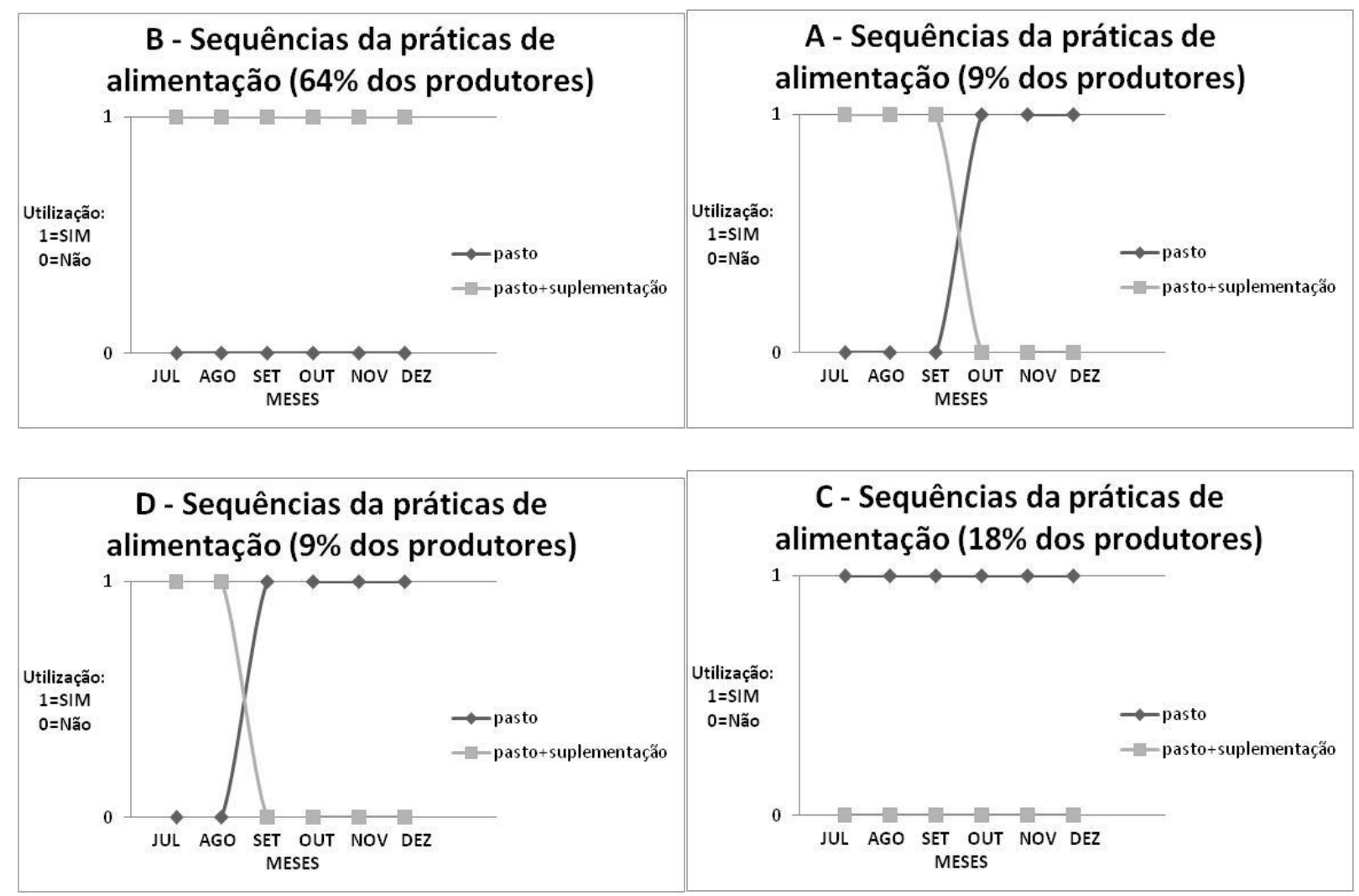

Figura 1. Tipos de sequências das práticas de alimentação, com base na fonte principal de alimento, em propriedades que exploram a ovinocaprinocultura na região das Chapadas - MA. A = sequência que utiliza o pasto (nativo ou nativo+cultivado) com transição para pasto com suplementação (Supl.); $\mathrm{B}=$ sequência que utiliza apenas o pasto (nativo ou nativo+cultivado) com suplementação (Supl.); $\mathrm{C}=$ sequência que utiliza apenas o pasto (nativo ou nativo+cultivado); $\mathrm{D}=$ sequência que utiliza o pasto (nativo ou nativo+cultivado) com suplementação (Supl.) e com transição para apenas o pasto.

Ainda na Figura 1 observa-se que estes problemas acontecem principalmente no mês de setembro, seja em sua proximidade ou distanciamento, mês que inicia o processo de queda na disponibilidade de forragem corroborando com as afirmações dos entrevistados os quais afirmam que os principais fatores que interferem na mudança do sistema de alimentação são os fatores climáticos associados à disponibilidade ou indisponibilidade de pastagem, seja ela nativa ou cultivada. Além disso, a indisponibilidade de grãos, em alguns casos produzidos na propriedade e o preço dos alimentos concentrados está entre os mais citados como agentes que interferiram nos seus graus de reatividade.

\section{CONCLUSÃO}

O sistema de produção de ovinos e caprinos na região sul do estado do Maranhão apresenta características típicas desta exploração comuns na região nordeste, sendo desenvolvida como atividade de subsistência, com demanda de assistência técnica especializada e com baixo nível tecnológico do ponto de vista nutricional.

A base alimentar dos ovinos e caprinos consiste no pasto nativo associado ao pasto cultivado com fornecimento de concentrado sem considerar os aspectos nutricionais, sendo influenciados pelos aspectos climáticos e de mercado (disponibilidade e preço). 


\section{REFERÊNCIAS}

1. Instituto Brasileiro de Geografia e Estatística. Estatísticas sobre pecuária, rebanho e produção [Internet]. Rio de Janeiro: IBGE; 2009 [cited 2016 Jan 9]. Available from: www.sidra.ibge.gov.br.

2. Gonçalves AL, Lana RP, Vieira RAM, Henrique DS, Mancio AB, Pereira JC. Avaliação de sistemas de produção de caprinos leiteiros na região sudeste do Brasil. Rev Bras Zootec. 2008;37:366-76.

3. Ingrant S, Cournut S, Dedieu B, Antheaume F. La conduite de la reproduction du troupeau de vaches allaitantes: modélisation des prises de decision. INRA Prod Anim. 2003;16:2618 .

4. Cournut S. Le fonctionnement des systèmes biologiques pilotés: simulation à événements discrets d'un troupeau ovin conduit en 3 agnelages en 2 ans [these]. Lyon: University Claude Bernard; 2001.

5. Costa RG, Almeida CC, Pimenta Filho EC, Holanda Junior EV, Santos NM. Caracterização do sistema de produção caprino e ovino na região semi-árida do estado da Paraíba, Brasil. Arch Zootec. 2008;57:195-205.

6. Leal MP. Novo zoneamento do estado do Maranhão. São Luís: SUDEMA; 1972.

7. Embrapa. Serviço Nacional de Levantamento e Conservação de Solos. Levantamento exploratório: reconhecimento de solos do estado do Maranhão. Rio de Janeiro: Embrapa/SNLCS; 1986. v. 2. (Boletim de pesquisa; $n^{\circ}$ 35).

8. Secretaria de Planejamento (Maranhão). Marco de referência do programa: as áreas de intervenção. São Luís; 1984.

9. Damasceno JC, Macombe C, Moinet MH, Pailleux JY, Cournut S, Dedieu B. Ver des projets d'élevage raisonnés en commun? Analyse de 12 démarches de commercialisation associant de petits groupes d'élevage laiters. In: Procédures dans 12èmes Rencontres Recherches Ruminants; Paris; 2005. Paris; 2005. p.212.

10. Francisco WCE. Aspectos Naturais do Maranhão [Internet]. Brasil Escola; 2016 [cited 2016 Jun 10]. Available from: http://brasilescola.uol.com.br/brasil/aspectos-naturaismaranhao.htm

11. Faria GA, Morais OR, Guimarães PHS. Análise da ovinocaprinocultura no Norte e Nordeste de Minas Gerais. Belo Horizonte: SEBRAE-MG, FAEMG, EMATER; 2004.

12. Alencar SP, Mota RA, Coelho MCOC, Nascimento SA, Abreu SRO, Castro RS. Perfil sanitário dos rebanhos caprinos e ovinos no sertão de Pernambuco. Cienc Anim Bras. 2010;11:131-40.

13. Vieira FJ, Santos LGP, Barros RFM, Araújo JLL. Quilombola of macacos community, São Miguel do Tapuio City, Piauí State: history, use and conservation of plant resources. Funct Ecosystems Comunities. 2008;2:81-7. 
14. Medeiros JX. Situação atual das cadeias produtivas. Brasília: Ministério da Ciência e Tecnologia. Conselho Nacional de Desenvolvimento Científico e Tecnológico. Coordenação Geral de Programa de Pesquisa em Agropecuária e Biotecnologia; 2001. (Reunião técnica. Apoio à cadeia produtiva da ovino-caprinocultura brasileira- relatório final).

15. Bandeira DA. 2005. Características sanitárias e de produção da caprinocultura nas microrregiões do Cariri do Estado da Paraíba [tese]. Recife: Universidade Federal Rural de Pernambuco; 2005.

16. Costa AD. Nível tecnológico, rentabilidade e cadeia produtiva da ovinocaprinocultura de corte no Estado do Ceará [dissertação]. Fortaleza: Universidade Federal do Ceará; 2007.

17. Alves LR. APL da caprinovinocultura da região central de Cabugi do Rio Grande do Norte [trabalho de conclusão de curso]. Natal: Universidade Federal do Rio Grande do Norte; 2005.

18. Porto LLMA, Salum WB, Alves C. Caracterização da ovinocaprinocultura de corte na região do Centro Norte Baiano. Rev Bras Gest Desenvolv Reg. 2013;9:281-96.

19. Dwyer CM. Genetic and physiological determinants of maternal behavior and lamb survival: implications for low-input sheep management. J Anim Sci. 2008;86:259-70.

20. Lima GFC, Silva JGM, Nobre FV, Barreto HFM. Produção estratégica de alimentos para a pecuária familiar no semiárido: alternativas para a formulação de rações na própria fazenda. Natal: EMPARN; 2009.

21. Underwood EJ, Suttle NF. The mineral nutrition of livestock. 3th ed. Midlothian: CABI; 1999.

22. Roehsig L. 2006. Análise das estratégias de alimentação de vacas leiteiras a partir das práticas adotadas pelo produtor [dissertação]. Maringá: Universidade Estadual de Maringá; 2006.

Recebido em: 17/09/2016 Aceito em: 28/05/2017 